\title{
AIP
}

\section{Identifying the influence of the intrinsic defects in Gd-doped $\mathrm{ZnO}$ thin-films}

T. H. Flemban, M. C. Sequeira, Z. Zhang, S. Venkatesh, E. Alves, K. Lorenz, and I. S. Roqan

Citation: Journal of Applied Physics 119, 065301 (2016); doi: 10.1063/1.4941434

View online: http://dx.doi.org/10.1063/1.4941434

View Table of Contents: http://scitation.aip.org/content/aip/journal/jap/119/6?ver=pdfcov

Published by the AIP Publishing

\section{Articles you may be interested in}

Defect-band mediated ferromagnetism in Gd-doped $\mathrm{ZnO}$ thin films

J. Appl. Phys. 117, 013913 (2015); 10.1063/1.4905585

Synthesis, characterization and thermoelectric properties of fine grains $\mathrm{Gd}$-doped $\mathrm{ZnO}$

AIP Conf. Proc. 1449, 319 (2012); 10.1063/1.4731561

On the origin of an additional Raman mode at $275 \mathrm{~cm}-1$ in N-doped $\mathrm{ZnO}$ thin films

J. Appl. Phys. 111, 063530 (2012); 10.1063/1.3697971

Structural and photoluminescence properties of $\mathrm{Gd}$ implanted $\mathrm{ZnO}$ single crystals

J. Appl. Phys. 110, 033534 (2011); 10.1063/1.3619852

Blueshift of near band edge emission in $\mathrm{Mg}$ doped $\mathrm{ZnO}$ thin films and aging

J. Appl. Phys. 95, 4772 (2004); 10.1063/1.1690091

\section{The new SR865 2 MHz Lock-In Amplifier ... \$7950}

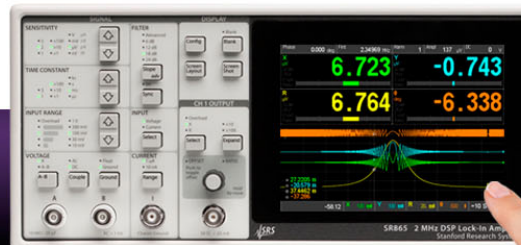

NRS Stanford Research Systems

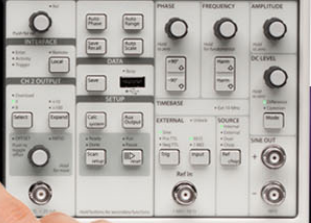

(॰)
Intuitive front-panel operation

Touchscreen data display

Save data \& screen shots to USB flash drive

Embedded web server and iOS app

. Synch multiple SR865s via $10 \mathrm{MHz}$ timebase I/O

View results on a TV or monitor (HDMl output)

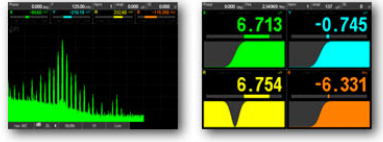

FFT displays
$1 \mathrm{mHz}$ to $2 \mathrm{MHz}$

$2.5 \mathrm{nV} / \sqrt{ } \mathrm{Hz}$ input noise $1 \mu$ s to 30 ks time constants 1.25 MHz data streaming rate

Sine out with DC offset

GPIB, RS-232, Ethernet \& USB 


\title{
Identifying the influence of the intrinsic defects in Gd-doped ZnO thin-films
}

\author{
T. H. Flemban, ${ }^{1}$ M. C. Sequeira, ${ }^{2}$ Z. Zhang, ${ }^{1}$ S. Venkatesh, ${ }^{1}$ E. Alves,${ }^{2}$ K. Lorenz, ${ }^{2}$ \\ and I. S. Roqan ${ }^{1, a)}$ \\ ${ }^{1}$ Physical Science and Engineering Division, King Abdullah University of Science and Technology (KAUST), \\ Thuwal 23955-6900, Saudi Arabia \\ ${ }^{2} I P F N$, Instituto Superior Técnico, Universidade de Lisboa, Campus Tecnológico e Nuclear, \\ Estrada Nacional 10,2695-066 Bobadela LRS, Portugal
}

(Received 22 November 2015; accepted 25 January 2016; published online 8 February 2016)

\begin{abstract}
Gd-doped $\mathrm{ZnO}$ thin films were prepared using pulsed laser deposition at different oxygen pressures and varied Gd concentrations. The effects of oxygen deficiency-related defects on the Gd incorporation, optical and structural properties, were explored by studying the impact of oxygen pressure during deposition and post-growth thermal annealing in vacuum. Rutherford Backscattering Spectrometry revealed that the Gd concentration increases with increasing oxygen pressure for samples grown with the same Gd-doped $\mathrm{ZnO}$ target. Unexpectedly, the $c$-lattice parameter of the samples tends to decrease with increasing Gd concentration, suggesting that Gd-defect complexes play an important role in the structural properties. Using low-temperature photoluminescence (PL), Raman measurements and density functional theory calculations, we identified oxygen vacancies as the dominant intrinsic point defects. PL spectra show a defect band related to oxygen vacancies for samples grown at oxygen deficiency. (C) 2016 AIP Publishing LLC.
\end{abstract}

[http://dx.doi.org/10.1063/1.4941434]

\section{INTRODUCTION}

Zinc oxide $(\mathrm{ZnO})$ has strong potential for advanced optoelectronic and spintronic applications ${ }^{1}$ due to its direct wide band gap $(\sim 3.3 \mathrm{eV})$, high exciton binding energy $(60 \mathrm{meV})$ and the availability of lattice-matched substrates. ${ }^{1,2}$ Doping $\mathrm{ZnO}$ with rare earth $\left(\mathrm{RE}^{3+}\right)$ ions enables further electrical, optical, and magnetic applications due to the unique character of partially filled $4 f$ shells. ${ }^{3-6}$ For example, Yang et al. ${ }^{4}$ reported a light-emitting diode prototype based on RE-doped $\mathrm{ZnO}$, capable of emitting across all wavelengths in the entire visible region. In addition, Gddoped/implanted $\mathrm{ZnO}$ exhibited room temperature (RT) ferromagnetic behavior that has been attributed to defect/impurity bands mediated by Gd dopants. ${ }^{7-12}$

Another interesting phenomenon that has been observed in Gd-doped $\mathrm{ZnO}$ is a Kondo-like effect, occurring due to a coupling between carriers and localized spin. ${ }^{13}$ More specifically, the electrostatic tuning of Kondo effect in Gd-doped $\mathrm{ZnO}$ was demonstrated for electrical-double layer transistor applications. ${ }^{11}$ For $\mathrm{ZnO}$ materials, the trivalent $\mathrm{RE}^{3+}$ ions are found to preferentially occupy substitutional or slightly displaced $\mathrm{Zn}$ sites. ${ }^{11,12,14}$ However, thus far, few detailed investigations of the effect of growth conditions on the optical and structural properties of $\mathrm{RE}$ in situ doped $\mathrm{ZnO}$ have been carried out.

In this work, we study the optical and structural properties of in situ Gd-doped $\mathrm{ZnO}$ films grown on lattice-matched substrate and identify the effect of intrinsic point defects (that accompany RE dopants) influenced by the oxygen pressure during deposition and post-growth thermal vacuum annealing on the Gd distribution.

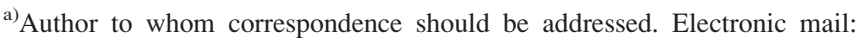
iman.roqan@kaust.edu.sa
}

\section{SAMPLE PREPARATION AND EXPERIMENTAL TECHNIQUES}

$\mathrm{Gd}$-doped $\mathrm{ZnO}$ thin films were prepared using pulsed laser deposition (PLD) on near lattice-matched (112̄0) $a-\mathrm{Al}_{2} \mathrm{O}_{3}$ substrate (lattice mismatch $\left.0.08 \%\right)^{15}$ that was used to reduce the formation of line defects. The major advantage of the PLD system is the possibility of transferring material components stoichiometrically from the prepared target to the film using proper gas pressures and laser conditions. ${ }^{16}$ The Gd-doped ZnO PLD targets were prepared by mixing 99.9-99.5 wt. \% $\mathrm{ZnO}$ (99.999\% pure) and $0.1-0.5 \mathrm{wt} . \%$ $\mathrm{Gd}_{2} \mathrm{O}_{3}(99.99 \%$ pure) powder in a ball mill for several hours. The material was subsequently dried before being compressed in a Hydraulic die $\left(\sim 5\right.$ Tonnes/in. $\left.{ }^{2}\right)$. These raw pellets were sintered at $1000^{\circ} \mathrm{C}$ for $12 \mathrm{~h}$ in air. $\mathrm{A} \mathrm{KrF}$ laser with a wavelength of $248 \mathrm{~nm}$ was used to deposit Gd-doped as well as undoped $\mathrm{ZnO}$ films.

Laser frequency, number of pulses, target-substrate distance, laser energy and substrate temperature were set at $10 \mathrm{~Hz}, 6500$ pulse, $50 \mathrm{~mm}, 520 \mathrm{~mJ}$, and $650^{\circ} \mathrm{C}$ respectively. The chamber was initially evacuated to a background pressure of $3 \times 10^{-5}$ Torr. For the deposition of different samples, the oxygen pressure $\left(P_{d}\right)$ varied from 5 to $100 \mathrm{mTorr}$. Two sets of samples were prepared - one using different targets with different $\mathrm{Gd}_{2} \mathrm{O}_{3}$ wt. \%, and the other using the same target and at different $P_{d}$, as shown in Table I. Some samples were subsequently annealed in vacuum $\left(\sim 7.5 \times 10^{-4}\right.$ mTorr $)$ at $350^{\circ} \mathrm{C}$ to examine the effect of vacuum annealing and oxygen deficiency-related defects on the structural and optical properties. For the purpose of comparison, undoped $\mathrm{ZnO}$ samples were prepared and deposited using similar PLD conditions; however, a larger number of pulses was used compared to Gd-doped $\mathrm{ZnO}$ samples to produce thicker samples with good structural and optical quality. 
TABLE I. Film thickness and Gd concentration of Gd-doped $\mathrm{ZnO}$ samples determined by RBS.

\begin{tabular}{lcccccc}
\hline \hline & Sample & Gd in target (wt. \%) & $\mathrm{P}_{\mathrm{d}}$ (mTorr) & Measured Gd (at. \%) & Thickness (nm) & Average measured Gd (wt. \%) \\
\hline Set 1: concentration & A & 0.25 & 25 & 0.07 & 241 & 0.13 \\
& B & 0.5 & 25 & 0.21 & 374 & 0.41 \\
Set 2: Pressure & D1 & 0.15 & 5 & 0.04 & 267 & 0.07 \\
& D2 & & 50 & 0.05 & 334 & 0.10 \\
& D3 & & 100 & 0.08 & 322 & 0.15 \\
\hline \hline
\end{tabular}

Rutherford backscattering spectrometry (RBS) was carried out using a beam of $1.8 \mathrm{MeV}$ Helium ions. The spectra were obtained using a silicon $\mathrm{p}$-i-n diode detector in IBM geometry. The RBS spectra were fitted with the NDF software package. ${ }^{17}$ X-Ray Diffraction (XRD) was performed on a Bruker D8 Discover high resolution XRD system by selecting the $\mathrm{CuK}_{\alpha 1}$ line with $\lambda=1.5406 \AA$. Micro-photoluminescence ( $\mu \mathrm{PL})$ was carried out using a Horiba JY LabRAM Aramis spectrometer with an LMU-15x-NUV lens in a Linkam THMS600 stage. The $\mu \mathrm{PL}$ measurements were performed at $77 \mathrm{~K}$ by an open loop cryostat using liquid nitrogen and a $325 \mathrm{~nm}$ (He-Cd) laser served as excitation source. Room temperature (RT) Raman spectra were acquired by a LabRAM Aramis Horiba JY spectrometer. The measurements were carried out in the $50-1200 \mathrm{~cm}^{-1}$ spectral range. The samples were excited using a Diode-Pumped Solid-State (DPSS) laser with a wavelength of $473 \mathrm{~nm}$. An Olympus $100 \times$ lens objective magnification was used to focus and collect the light scattered from the samples. The emitted light was collected by a spectrograph with a grating of 1800 lines/mm and a CCD camera cooled by liquid nitrogen.

\section{RESULTS AND DISCUSSIONS}

Film thickness and Gd concentration were evaluated by RBS measurements for both sets of samples, as summarized in Table I. The RBS spectra of samples that were grown at different Gd concentrations and at different $P_{d}$ are shown in Figures 1(a) and 1(b), respectively. For Gd-doped $\mathrm{ZnO}$ Samples, Figure 1(a) and Table I indicate that Gd incorporation in the target changes the sample thickness. This can be due to a change in the density of the target and therefore its thermal conductivity, which depends on the impurity composition. ${ }^{18,19}$ The data reported in Table I shows that the Gd concentration in the films is slightly different from that in the corresponding targets. It is known that the transfer ratio of the species from the target to the film depends on the type of the atoms. Each chemical species has different angular distribution in the plume. In addition, the gaseous pressure and the laser fluence on the target affect the transfer ratio, depending on the mass and charge state of the transferred ions. $^{18}$

Figure 1(b) shows RBS spectra for samples D1, D2, and D3 grown with the same $\mathrm{GdZnO}$ target but under different oxygen pressures (Set 2). The fit results are summarized in Table I. Figure 2(a) indicates that Gd concentration in $\mathrm{ZnO}$ matches the target concentration in sample D3 but decreases as $P_{d}$ decreases (i.e., under oxygen poor conditions) showing that optimizing the background oxygen pressure is important for maintaining the equilibrium composition of the target in the as-grown samples. ${ }^{20}$ The sample D1 grown in oxygen poor conditions furthermore shows increased surface roughness as suggested by the distortion of the Zn-barrier in the RBS spectrum. The increased straggling due to this surface roughness causes the elevated yield between the signals for $\mathrm{Al}$ and $\mathrm{Zn}$ (around channels 400-550) and is well described by the roughness models implemented in the NDF code. Note that the small peak around channel no 435 is not due to the sample but due to a silicon contamination originating from silicon paste used to mount the samples and transferred to the surface during ultra-sound cleaning. Due to high surface roughness it could not be completely removed. In order to confirm the influence of oxygen deficiency on Gd concentration, sample D3 (grown at relatively high $P_{d}=100 \mathrm{mTorr}$ ) was post-annealed in vacuum with an annealing temperature of $350{ }^{\circ} \mathrm{C}$, chosen to be above the oxygen binding energy. ${ }^{21}$ Annealing the sample at oxygen deficiency condition resulted in a reduction in the Gd concentration, as shown in Figure 2(a) and Table I, which is in line with the results of samples grown in oxygen poor conditions. This change in Gd concentration may be due to the change of the stoichiometric ratio of $\mathrm{ZnO}$ with vacuum annealing. However, it should be noted that $\mathrm{RE}$ atom diffusion in implanted $\mathrm{ZnO}$ single crystals was seen to set in at considerably higher temperatures around $1000{ }^{\circ} \mathrm{C},{ }^{14}$ suggesting that sample morphology and crystal quality play an important role.

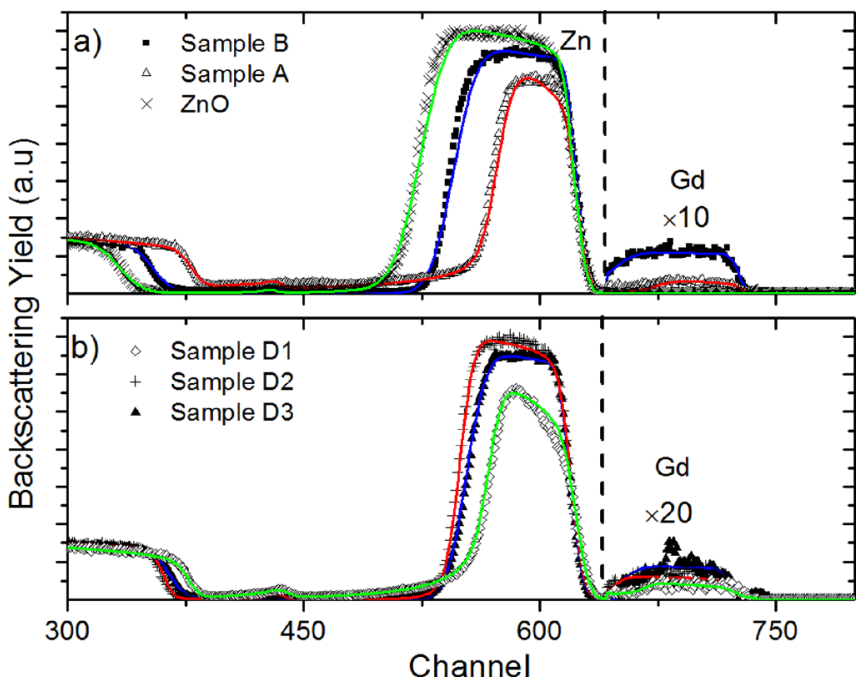

FIG. 1. RBS random spectra for Gd doped $\mathrm{ZnO}$ samples deposited by PLD on $a-\mathrm{Al}_{2} \mathrm{O}_{3}$ (a) for different concentration of $\mathrm{Gd}$ at $P_{d}=25 \mathrm{mTorr}$ (note that undoped $\mathrm{ZnO}$ is thicker due to a larger number of pulses during PLD compared to $G d$-doped samples), (b) same concentration at different $P_{d}$. 

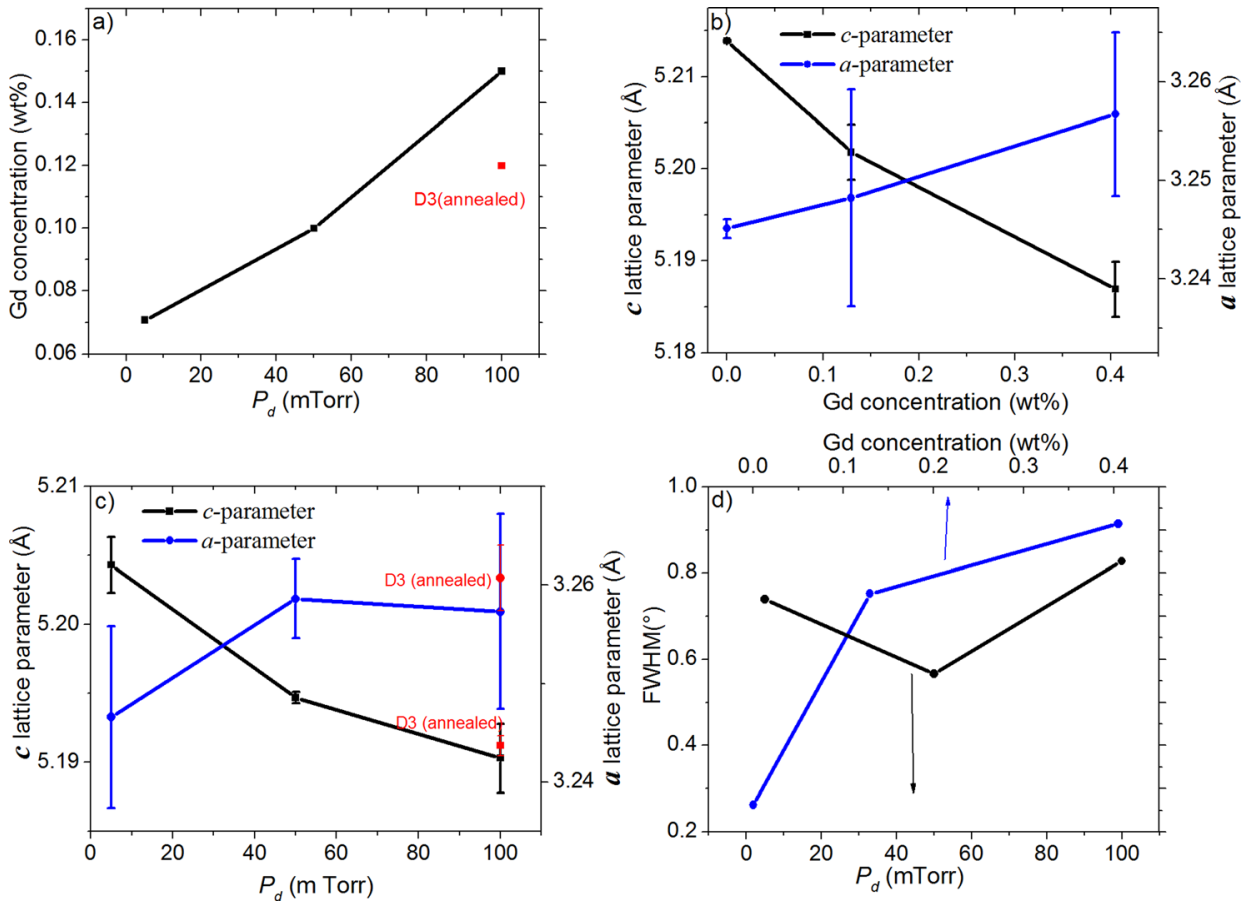

FIG. 2. (a) The effect of increasing $P_{d}$ and vacuum annealing on Gd concentration. Variation of parameter $c$ and $a$ estimated by XRD as (b) a function of the Gd concentration and (c) $P_{d}$. (The vertical bars indicating the errors). (d) The FWHM of the (004) rocking curves as a function of the Gdconcentration, and $P_{d}$.
Sample quality and lattice parameters were evaluated using XRD. Long range $2 \theta-\omega$ scans only show the symmetric reflections 002, 004 and 006 of wurtzite $\mathrm{ZnO}$ showing that the films are c-axis oriented. Furthermore, the asymmetric (104) reflections, although broad, were found in the positions expected for the wurtzite lattice revealing a single crystalline structure for all samples but indicating a high mosaicity. No phase segregation or Gd clustering was observed for any of the samples. The lattice parameters were obtained using the Extended Bond Method ${ }^{22}$ with the (004) and (104) planes. The center and full width at half maximum (FWHM) for each rocking curve were determined by fitting the experimental data with asymmetric Pseudo-Voigt functions. The uncertainties given in Table II were estimated considering the error of finding the curve centers. Figures 2(b) and 2(c) and Table II show the lattice parameters for the same two sets of samples presented in Table I. For Set 1 (Sample A and B), the $a$-parameter tends to increase while the $c$-parameter decreases with $\mathrm{Gd}$ incorporation compared to an undoped $\mathrm{ZnO}$, as shown in Table II. The shrinkage of $c$-parameter suggests the presence of an inclusion of vacancies that accompany $\mathrm{Gd}$ dopants in $\mathrm{ZnO}$ - a phenomenon that can arise due to crystal distortion during doping. ${ }^{11}$ For Set 2 with varying $P_{d}$, the $c$-parameter contracts with increasing $P_{d}$ (oxygen-rich environment), as shown in Figure 2(c). It should also be noted that, based on the RBS results, Gd concentration increases with increasing $P_{d}$ (Figure 2(a)). Therefore, the $c$-parameter contraction at higher Gd concentrations is consistent with the results obtained for Set 1 . We also investigate crystal quality by studying the FWHM of the rocking curves. Figure 2(d) shows that FWHM of the 004 rocking curves increases with the Gd concentration. Rocking curve broadening of the symmetric reflections can be due to a short lateral coherence length or due to mosaic tilt. The latter can be caused for example by dislocations. A largeramount of $\mathrm{Gd}$ in a sample increases the likelihood of defect formation which in turn can broaden the rocking curves. However, a different grain size in the two samples cannot be excluded. $^{23}$

For a simple substitution of $\mathrm{Gd}$ on $\mathrm{Zn}$ sites, an increase in the lattice parameter values would be expected due to the larger ionic radius of $\mathrm{Gd}$ compared to $\mathrm{Zn}$. In particular, for pseudomorphic growth on the near lattice matched substrate the $c$-parameter should expand while the in-plane $a$ parameter should remain unchanged. The fact that both lattice parameters change confirms that the growth is not pseudomorphic (the $a$-parameter tends to increase with increasing Gd concentration). The reduction of the $c$-parameter value with $\mathrm{Gd}$

TABLE II. The measured lattice parameters $a$ and $c$ for Gd-doped $\mathrm{ZnO}$ samples with the measured Gd concentrations.

\begin{tabular}{|c|c|c|c|c|c|c|c|}
\hline & Sample & RBS measured Gd (wt. \%) & $P_{d}($ mTorr $)$ & $a(\AA)$ & Error da $(\AA)$ & $c(\AA)$ & Error dc $(\AA)$ \\
\hline \multirow[t]{3}{*}{ Set 1 : concentration } & Undoped $\mathrm{ZnO}$ & 0 & 25 & 3.245 & 0.001 & 5.214 & 0.001 \\
\hline & A & 0.07 & & 3.248 & 0.011 & 5.202 & 0.003 \\
\hline & B & 0.21 & & 3.257 & 0.008 & 5.187 & 0.003 \\
\hline \multirow[t]{4}{*}{ Set 2: Pressure } & D1 & 0.04 & 5 & 3.246 & 0.009 & 5.204 & 0.002 \\
\hline & D2 & 0.05 & 50 & 3.258 & 0.004 & 5.195 & 0.001 \\
\hline & D3 & 0.08 & 100 & 3.257 & 0.010 & 5.190 & 0.003 \\
\hline & D3 (annealed) & 0.06 & & 3.261 & 0.003 & 5.191 & 0.001 \\
\hline
\end{tabular}


concentration, despite the substitution of Gd on $\mathrm{Zn}$ sites, can only be explained by the formation of Gd-defect complexes. Therefore, for further investigation, density functional theory (DFT) calculations, which were performed using the Vienna Ab-initio Simulation Package (VASP) ${ }^{24,25}$ with projector augmented wave potentials, and a plane-wave expansion up to $600 \mathrm{eV} .{ }^{26}$ Reasonably sufficient $\mathrm{k}$-meshes for different supercells $(3 \times 3 \times 3$ mesh for 72-atom supercell) were sampled to optimize both the volume and ion positions. The exchange and correlations were treated within the PerdewBurke-Ernzerhof generalized gradient approximation (GGA). For the localized $\mathrm{Zn} 3 d$ and $\mathrm{Gd} 4 f$ states, Hubbard $U$ correction was taken into account with $\mathrm{U}_{\text {eff }}$ at $5 \mathrm{eV}$ for $\mathrm{Zn} d$ and $6 \mathrm{eV}$ for $\mathrm{Gd} f$ states, ${ }^{27}$ respectively, to deal with Coulomb interaction. All configurations were fully relaxed until the forces per atom are converged to less than $0.02 \mathrm{eV} / \mathrm{A}$. The energy convergence was set to $5 \times 10^{-5} \mathrm{eV}$. Our simulations show that the $a$ - and $c$-lattice parameters change in Gd doped $\mathrm{ZnO}$ with respect to those of pure $\mathrm{ZnO}(a=3.236 \AA$, $c=5.204 \AA$ ) as shown in Fig. 3. The isolated oxygen vacancy $\left(\mathrm{V}_{\mathrm{O}}\right)$ introduces a shrinkage in both lattice parameters whereas the isolated $\mathrm{Zn}$ vacancy $\left(\mathrm{V}_{\mathrm{Zn}}\right)$ enlarge the $c$-lattice parameter. Furthermore, the isolated $\mathrm{Gd}$ atoms in the substitutional sites $\left(\mathrm{Gd}_{\text {sub }}\right)$ enlarge both lattice parameter values as expected. For $\mathrm{Gd}_{\mathrm{sub}}-\mathrm{V}_{\mathrm{O}}$ and $\mathrm{Gd}_{\mathrm{sub}}-2 \mathrm{~V}_{\mathrm{O}}$ complexes, we show the parameters of the energetically most favourable values, which were determined by minimizing the total energy of a series of configurations constructed in a 72-atom supercell. This indicates a preference for a low density of $\mathrm{Gd}_{\text {sub }}-\mathrm{V}_{\mathrm{O}}$ complexes, which supports our assumption. Fig. 3 shows that $\mathrm{V}_{\mathrm{O}}$ defects shrink the lattice, counteracting the expansion induced by $\mathrm{Gd}_{\text {sub }}$ impurities when they form $\mathrm{Gd}_{\mathrm{sub}}-\mathrm{V}_{\mathrm{O}}$ and $\mathrm{Gd}-2 \mathrm{~V}_{\mathrm{O}}$ complexes. Note that $\mathrm{Gd}-2 \mathrm{~V}_{\mathrm{O}}$ does not modify the $a$-parameter. This result is in line with the XRD results. Gd on the $\mathrm{Zn}$ site should have a tetrahedral coordination with the bond length along the $c$-axis slightly shorter than the bond-lengths along the three equivalent $\mathrm{O}$-sites in the basal

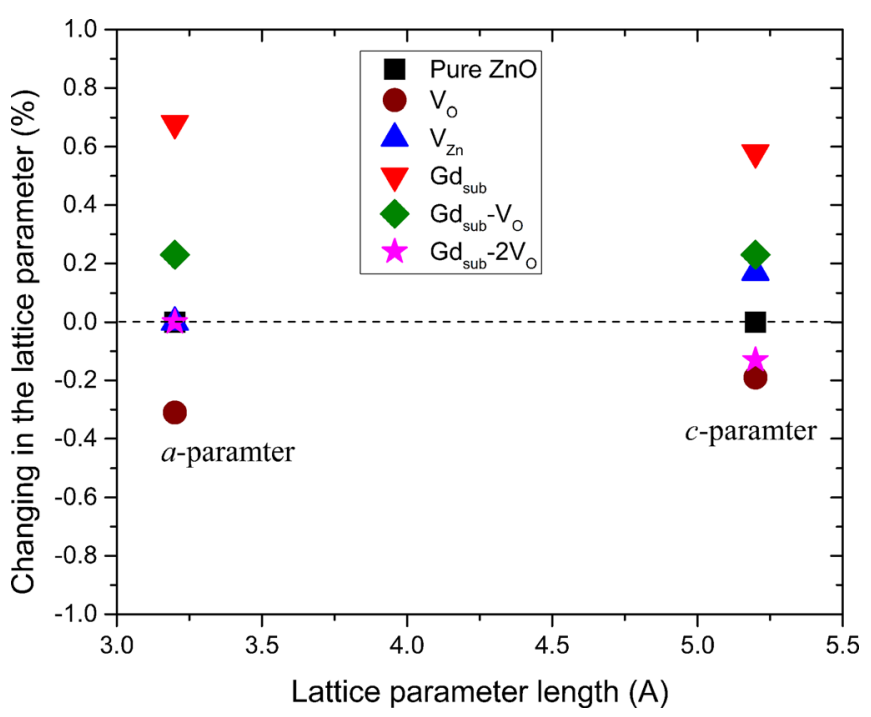

FIG. 3. DFT calculations of the length of the lattice parameters $a$ and $c$ by introducing vacancies and substitutional Gd impurities in the $\mathrm{ZnO}$ supercell. plane. Clustering of $\mathrm{Gd}$ on adjacent substitutional sites within the basal plane is also consistent with our observations. It should be noted that interstitial defects in $\mathrm{ZnO}$ were shown to be very mobile at temperatures below room temperature and should play a minor role in the present observations. ${ }^{28}$ Therefore, assuming that Gd-oxygen deficiency complexes (mainly, $\mathrm{Gd}-\mathrm{V}_{\mathrm{O}}$ and $\mathrm{Gd}-2 \mathrm{~V}_{\mathrm{O}}$ ) are at the origin of the $c$-contraction, it can be posited that a complex equilibrium between the formation of isolated oxygen vacancy (which should be increased at low $P_{d}$ ) and the formation of $\mathrm{Gd}-\mathrm{V}_{\mathrm{O}}$ complexes exists, which depends on both $\mathrm{Gd}$ concentration (which increases at higher $P_{d}$ ) and $\mathrm{V}_{\mathrm{O}}$-concentration (which decreases at higher $P_{d}$ ).

Vacuum annealing is expected to create oxygen deficiency conditions and may affect the Gd-oxygen deficiency complexes. RBS shows a decrease in Gd content, while the lattice parameters remain unchanged (Fig. 2(c)) within the limits of experimental uncertainties. It is worth noting that, for implanted samples, RE ions were only seen to diffuse at considerably higher temperatures around $1000^{\circ} \mathrm{C} .^{14}$ The effect of $\mathrm{V}_{\mathrm{O}}$ on $\mathrm{Gd}$ diffusion is not clear at this point. However, there is no evidence of a significant change of the number of $\mathrm{Gd}-\mathrm{V}_{\mathrm{O}}$, since the lattice parameters remain unchanged.

Optical spectroscopy is one of the most powerful tools that can be used to study the influence of the intrinsic point defects of the materials. ${ }^{29,30}$ The type of defects can be identified by studying defect band emission from PL spectra of the samples. For Set 1, Figure 4(a) shows the PL spectra of Sample A and B, both of which reveal a green band emission centered at $\sim 525 \mathrm{~nm}(\sim 2.36 \mathrm{eV})$, which increases with $\mathrm{Gd}$ concentration. This band increases with Gd concentration. The origin of this band has been suggested to be related to oxygen vacancies $\left(\mathrm{V}_{\mathrm{O}}\right)$ or zinc vacancies $\left.\left(\mathrm{V}_{\mathrm{Zn}}\right)\right)^{31-33}$ Other studies found that this green band in $\mathrm{ZnO}$ can be attributed also to complex defects such as zinc interstitial $\left(\mathrm{Zn}_{\mathrm{i}}\right)^{34}$ or $\mathrm{O}_{\mathrm{Zn}}$ antisites. ${ }^{35}$ Moreover, deep-level transient spectroscopy (DLTS), ${ }^{36,37}$ electron paramagnetic resonance, ${ }^{38,39}$ and optically detected magnetic resonance, ${ }^{37,39,40}$ have confirmed that this band is related to electron transition from $\mathrm{V}_{\mathrm{O}}$, as a deep donor level to recombine with a hole in the valence band. ${ }^{36,37}$ Thermo-luminescence measurements provide evidence for the presence of two potential emission centers for the green luminescence in $\mathrm{ZnO}$ that are associated with a pair of $\mathrm{V}_{\mathrm{O}}-\mathrm{V}_{\mathrm{Zn}}$ related defects. ${ }^{33}$ Therefore, PL confirms that large numbers of $\mathrm{V}_{\mathrm{O}}$ are present in the doped samples. This is in agreement with the assumption that these vacancies may be responsible for the reduction in the $c$-parameter as $\mathrm{Gd}$ concentration increases, and in particular, when $\mathrm{Gd}-\mathrm{V}_{\mathrm{O}}$ complexes are formed.

Figure 4(b) shows the PL spectra for the samples grown at different $P_{d}$ (Set 2). As can be seen, when $P_{d}$ increases from 5 to $100 \mathrm{mTorr}$, the green emission intensity decreases significantly, corroborating the assumption that this band is related to $\mathrm{V}_{\mathrm{O}}$. With increasing $P_{d}$, the band experiences a redshift from $\sim 483 \mathrm{~nm}(\sim 2.55 \mathrm{eV})$ to $\sim 500 \mathrm{~nm}(\sim 2.48 \mathrm{eV})$, respectively, and a red band becomes dominant, for sample grown at $100 \mathrm{mTorr}$ (Sample D3). Such a red band was attributed to electron transitions from oxygen interstitial $\left(\mathrm{O}_{\mathrm{i}}\right)$ 


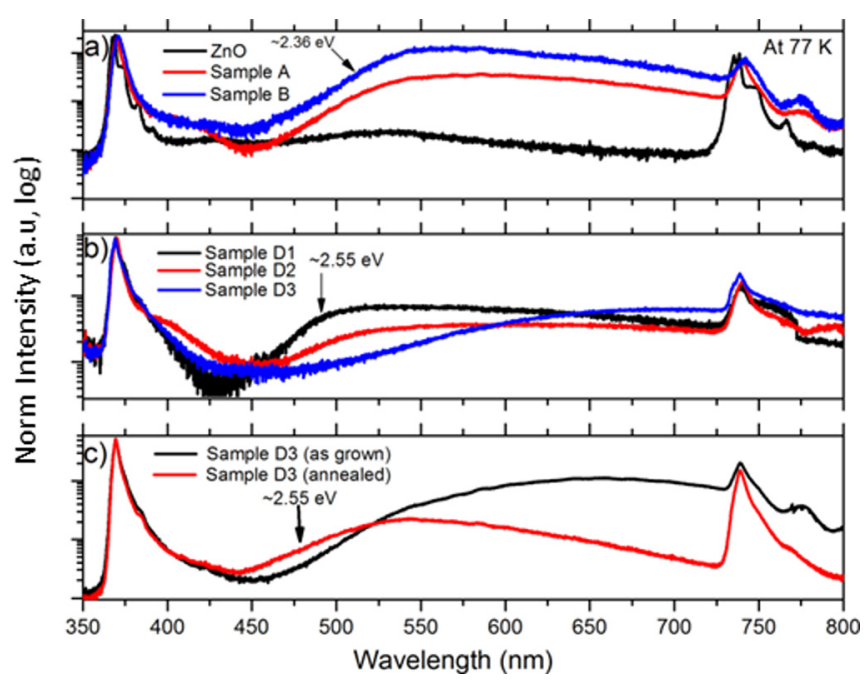

FIG. 4. PL spectra for (a) Sample A, and B compared to undoped $\mathrm{ZnO}$ grown at different concentrations, (b) Samples D1, D2 and D3 grown at different $P_{d}$, (c) as grown and vacuum annealing $\mathrm{Gd}$ doped $\mathrm{ZnO}$ samples grown under high pressure $P_{d}=100 \mathrm{mTorr}$ (Sample D3).

or $\mathrm{V}_{\mathrm{Zn}}$ levels that are created in oxygen-rich conditions, ${ }^{33,41-44}$ as confirmed by DLTS. ${ }^{36,37}$ In order to confirm the type of defects in these samples, PL measurements were carried out for the vacuum-annealed Sample D3 grown at $100 \mathrm{mTorr}$ (Figure 4(c)). As expected for annealing in oxygen deficient conditions, the PL spectrum of Sample D3 (annealed) shows a significant reduction in the red band, whereby the spectrum becomes dominated by the green band, which is attributed to $\mathrm{V}_{\mathrm{O}}$. No significant change in the $c$-parameter is observed for vacuum annealed samples, although $\mathrm{V}_{\mathrm{O}}$ concentration is higher and a significant reduction in Gd concentration is observed. These findings suggest that the observed changes in lattice parameters in some samples are neither due to isolated $V_{O}$ nor to isolated $\mathrm{Gd}_{\mathrm{Zn}}$ but rather to the formation of $\mathrm{Gd}$-defect complexes.

RT Raman spectroscopy was carried out to confirm the type of the point defects. It is known that the space group of wurtzite $\mathrm{ZnO}$ is $\mathrm{C}_{6}^{4}$ v with two formula units per primitive cell. Figure 5 shows typical wurtzite $\mathrm{ZnO}$ Raman spectra for Sample A and B and an undoped sample of $\mathrm{ZnO}$. Some $\mathrm{ZnO}$ phonon modes are observed, dominated by $E_{2}(l o w)$ and $E_{2}\left(\right.$ high) at 99.8 and $439 \mathrm{~cm}^{-1}$, respectively, as shown in Figure 5(a). On the other hand, the other modes, such as $\mathrm{A}_{1}$ (TO), $\mathrm{A}_{1}$ (LO), $\mathrm{E}_{1}$ (TO), and $\mathrm{E}_{1}$ (LO) (at 380, 579, 409.5, and $588 \mathrm{~cm}^{-1}$, respectively) are overlapped with the lines of the sapphire substrate at $380,431,450$, and $577 \mathrm{~cm}^{-1}$ as indicated by the asterisks. ${ }^{1,45-47}$ The two nonpolar $E_{2}$ (low) and $E_{2}(h i g h)$ are Raman active, since $E_{2}(h i g h)$ is related to the vibration of oxygen atoms, while the $E_{2}(l o w)$ is related to the heavy $\mathrm{Zn}$ in the sublattice in the wurtzite structure. ${ }^{1}$ Figures 5(a) and 5(b) show that, as Gd concentration in
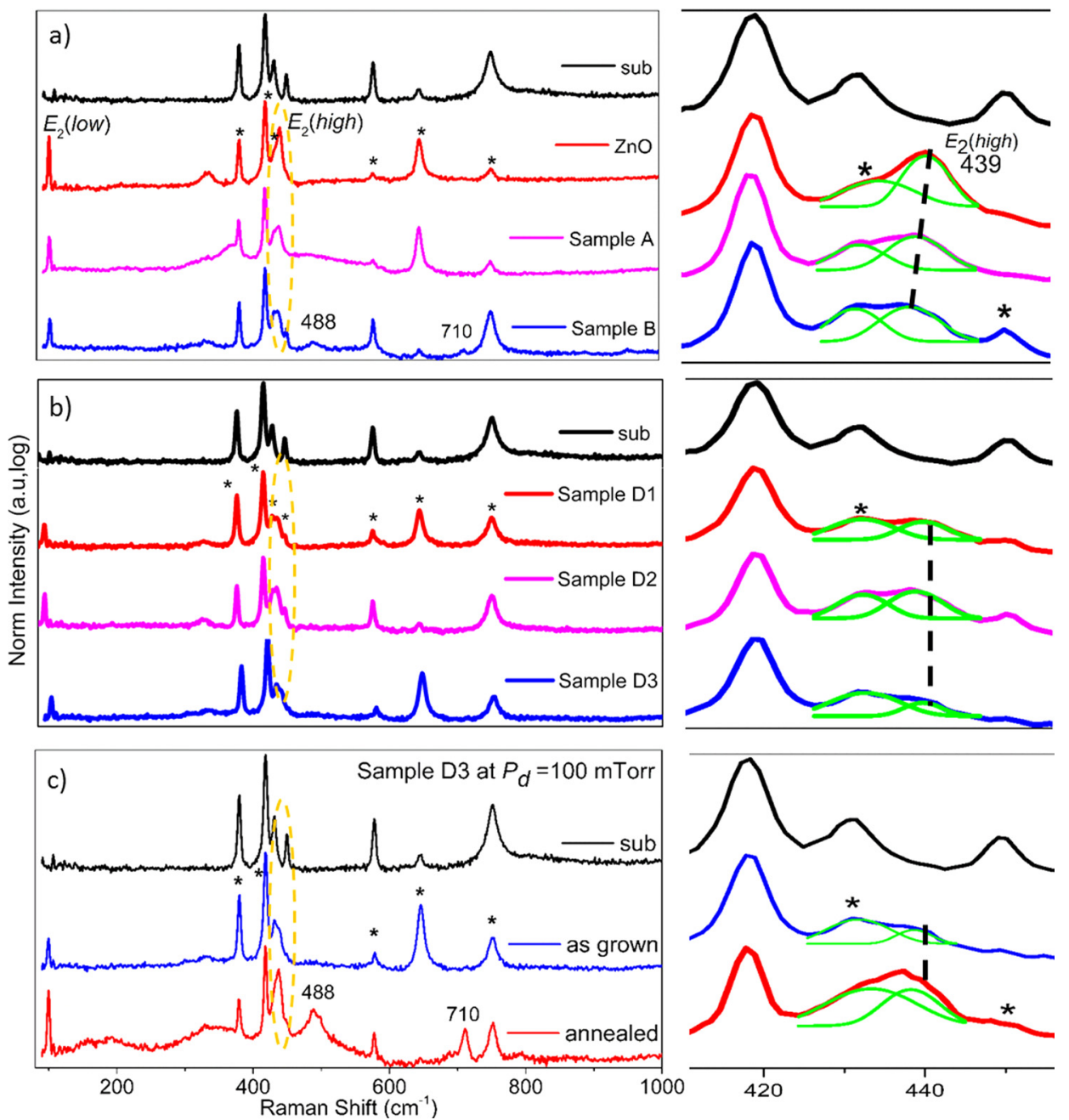

FIG. 5. Raman spectra for (a) samples deposited at different concentrations (Sample A and B); (b) samples deposited with different pressures (Sample D1, D2 and D3); (c) annealed and as grown samples (Sample D3). The inset shows the magnified range circled by a yellow dashed line in figs. (a), (b) and (c) and the green line is the peak fit to show $E_{2}$ (high) peak shift. The peaks labelled with $(*)$ are emerged from the sapphire substrate (the black spectrum) 
Gd-doped $\mathrm{ZnO}$ films decreases, the phonon mode $E_{2}($ high $)$ peak shifts toward higher frequencies. The possible mechanisms that can be responsible for such a shift are (i) the biaxial strain, ${ }^{48}$ (ii) phonon localization, ${ }^{49,50}$ and (iii) laserinduced heating in materials and tensile strain during Raman measurements. ${ }^{49,50}$ As $E_{2}$ (high) peak is expected to shift to the higher frequency value as the compressive biaxial stress increases (and $c$-parameter value decreases), we assume the unusual shift of $E_{2}(h i g h)$ peak to lower frequencies as $c$-parameter decreases in our samples can be due the second assumption, which is phonon localization by defects, such as those related to oxygen deficiency, ${ }^{51}$ zinc excess or surface impurities, are in line with the PL and XRD measurements, suggesting that defects related to oxygen deficiency such as $\mathrm{V}_{\mathrm{O}}$ accompanied Gd dopants. Furthermore, we excluded the explanation related to laser-induced heating in materials and tensile strain during Raman as all samples were measured at the same time using the same conditions, and the laser power on the samples was $\sim 0.07 \mathrm{~mW}$ (to avoid the heating effect). Therefore, we assume that $E_{2}(h i g h)$ depends on oxygen concentration and related defects. ${ }^{51}$ This assertion is supported by the PL measurements. Figure 5(b) shows the effect of $P_{d}$, where a slight shift of $E_{2}($ high $)$ peak to the lower frequencies for samples deposited at 50 mTorr compared to that deposited at 5 and 100 mTorr can be noted. This phenomenon is likely due to the combination effect of oxygen concentration and Gd concentration that are changed by modifying $P_{d}$. In this case, the influence of oxygen-related defects can be compensated by that of Gd concentration. Figure 5(c) shows the effect of vacuum annealing. No shift is observed for $E_{2}($ high $)$ peak. However, a new peak at $710 \mathrm{~cm}^{-1}$ emerges and the intensity of the peak at $488 \mathrm{~cm}^{-1}$ increases significantly after vacuum annealing under oxygen deficiency conditions. These two peaks are also observed in Sample B (with higher Gd concentration, 0.404 wt. \%), which have been reported to appear with the inclusion of metallic dopants in $\mathrm{ZnO}$ and are enhanced significantly with the annealing, ${ }^{52,53}$ which is in line with our results, as shown in Figures 5(a) and 5(c). The peak at $488 \mathrm{~cm}^{-1}$ was reported to be due to a local vibrational mode of a defect/impurity. ${ }^{52}$ On the other hand, the peak at $710 \mathrm{~cm}^{-1}$ may be related to the intrinsic defects surrounding Gd ions, which are also present at higher Gd concentrations (Sample B). $\mathrm{V}_{\mathrm{O}}$ can be created when the film is annealed under vacuum and the activation energy required to develop $\mathrm{V}_{\mathrm{O}}$ through $\mathrm{ZnO}$ is reported to be $\sim 0.06 \mathrm{eV}^{54}$ Therefore, we assume that a diffusion of $\mathrm{V}_{\mathrm{O}}$ may take place at $350{ }^{\circ} \mathrm{C}$ and change the local arrangement of the atoms surrounding the Gd impurity, causing the $710 \mathrm{~cm}^{-1}$ peak to emerge after annealing under vacuum. ${ }^{47}$

\section{CONCLUSIONS}

In summary, the Gd inclusion in $\mathrm{ZnO}$ decreases for samples grown in oxygen-poor conditions. XRD indicates that $\mathrm{ZnO}$ experiences a decrease of the $c$ lattice parameter as the Gd concentration increases, which was attributed to the formation of $\mathrm{Gd}-\mathrm{V}_{\mathrm{O}}$ and $\mathrm{Gd}-2 \mathrm{~V}_{\mathrm{O}}$ complexes with the aid of DFT calculations. PL measurements showed band emission related to $\mathrm{V}_{\mathrm{O}}$ for samples grown or annealed under oxygen deficient conditions. Raman spectroscopy results are consistent with these changes in the oxygen sublattice and a line at $710 \mathrm{~cm}^{-1}$ was tentatively attributed to specific local arrangement surrounding the $\mathrm{Gd}$ atom due to $\mathrm{V}_{\mathrm{O}}$ diffusion. The findings reported in this paper can be important for devices based on RE-doped $\mathrm{ZnO}$ materials.

\section{ACKNOWLEDGMENTS}

We acknowledge financial support from the General Directorate of Research Grants, from King Abdul-Aziz City of Science and Technology.

${ }^{1}$ U. Ozgur, Y. I. Alivov, C. Liu, A. Teke, M. A. Reshchikov, S. Dogan, V. Avrutin, S. J. Cho, and H. Morkoc, J. Appl. Phys. 98(4), 041301 (2005).

${ }^{2}$ B. K. Meyer, H. Alves, D. M. Hofmann, W. Kriegseis, D. Forster, F. Bertram, J. Christen, A. Hoffmann, M. Strabburg, M. Dworzak, and U. Haboeck, Phys. Status Solidi B 241(2), 231 (2004).

${ }^{3}$ Z. P. F. Jiang, Y. Zang, and X. Fu, J. Adv. Ceram. 2(3), 201 (2013).

${ }^{4}$ Y. Yang, Y. P. Li, C. X. Wang, C. Zhu, C. Y. Lv, X. Y. Ma, and D. R. Yang, Adv. Opt. Mater. 2(3), 240 (2014).

${ }^{5}$ A. Douayar, P. Prieto, G. Schmerber, K. Nouneh, R. Diaz, I. Chaki, S. Colis, A. El Fakir, N. Hassanain, A. Belayachi, Z. Sekkat, A. Slaoui, A. Dinia, and M. Abd-Lefdil, Eur. Phys. J.: Appl. Phys. 61(1), 10304 (2013).

${ }^{6}$ J. Kennedy, G. V. M. Williams, P. P. Murmu, and B. J. Ruck, Phys. Rev. B 88(21), 214423 (2013).

${ }^{7}$ V. Ney, S. Ye, T. Kammermeier, A. Ney, H. Zhou, J. Fallert, H. Kalt, F. Y. Lo, A. Melnikov, and A. D. Wieck, J. Appl. Phys. 104(8), 083904 (2008).

${ }^{8}$ K. Potzger, Z. Shengqiang, F. Eichhorn, M. Helm, W. Skorupa, A. Mucklich, J. Fassbender, T. Herrmannsdorfer, and A. Bianchi, J. Appl. Phys. 99(6), 63906 (2006).

${ }^{9}$ I. S. Roqan, S. Venkatesh, Z. Zhang, S. Hussain, I. Bantounas, J. B. Franklin, T. H. Flemban, B. Zou, J. S. Lee, U. Schwingenschlogl, P. K. Petrov, M. P. Ryan, and N. M. Alford, J. Appl. Phys. 117(7), 073904 (2015).

${ }^{10}$ S. Venkatesh, J. B. Franklin, M. P. Ryan, J. S. Lee, H. Ohldag, M. A. McLachlan, N. M. Alford, and I. S. Roqan, J. Appl. Phys. 117(1), 013913 (2015).

${ }^{11}$ M. Subramanian, P. Thakur, M. Tanemura, T. Hihara, V. Ganesan, T. Soga, K. H. Chae, R. Jayavel, and T. Jimbo, J. Appl. Phys. 108(5), 053904 (2010).

${ }^{12}$ P. P. Murmu, R. J. Mendelsberg, J. Kennedy, D. A. Carder, B. J. Ruck, A. Markwitz, R. J. Reeves, P. Malar, and T. Osipowicz, J. Appl. Phys. 110(3), 033534 (2011).

${ }^{13}$ Y. Li, R. Deng, W. Lin, Y. Tian, H. Peng, J. Yi, B. Yao, and T. Wu, Phys. Rev. B 87(15), 155151 (2013).

${ }^{14}$ S. M. C. Miranda, M. Peres, T. Monteiro, E. Alves, H. D. Sun, T. Geruschke, R. Vianden, and K. Lorenz, Opt. Mater. 33(7), 1139 (2011).

${ }^{15}$ P. Fons, K. Iwata, A. Yamada, K. Matsubara, S. Niki, K. Nakahara, T. Tanabe, and H. Takasu, Appl. Phys. Lett. 77(12), 1801 (2000).

${ }^{16}$ T. Yano, T. Ooie, M. Yoneda, and M. Katsumura, J. Mater. Sci. Lett. 15(22), 1994 (1996).

${ }^{17}$ W.-K. Chu, J. W. Mayer, and M.-A. Nicolet, Backscattering Spectrometry (Academic Press, Inc., 1978).

${ }^{18}$ D. Bauerle, in Laser Processing and Chemistry (Springer, Heidelberg, 2011), p. 489.

${ }^{19}$ C. B. Arnold and M. J. Aziz, Appl. Phys. A: Mater. Sci. Process. 69, S23 (1999).

${ }^{20}$ F. Claeyssens, A. Cheesman, S. J. Henley, and M. N. R. Ashfold, J. Appl. Phys. 92(11), 6886 (2002)

${ }^{21}$ A. Janotti and C. G. Van de Walle, Phys. Rev. B 76(16), 165202 (2007).

${ }^{22}$ N. Herres, L. Kirste, H. Obloh, K. Kohler, J. Wagner, and P. Koidl, Mater. Sci. Eng. B 91, 425 (2002).

${ }^{23}$ H. Gomez and M. de la L. Olvera, Mater. Sci. Eng. B 134, $20-26$ (2006).

${ }^{24}$ G. Kresse and J. Hafner, Phys. Rev. B 47(1), 558 (1993).

${ }^{25}$ G. Kresse and D. Joubert, Phys. Rev. B 59(3), 1758 (1999).

${ }^{26}$ P. E. Blochl, Phys. Rev. B 50(24), 17953 (1994).

${ }^{27}$ S. L. Dudarev, G. A. Botton, S. Y. Savrasov, C. J. Humphreys, and A. P. Sutton, Phys. Rev. B 57(3), 1505 (1998). 
${ }^{28}$ K. Lorenz, M. Peres, N. Franco, J. G. Marques, S. M. C. Miranda, S. Magalhaes, T. Monteiro, W. Wesch, E. Alves, and E. Wendler, in OxideBased Materials and Devices II, edited by F. H. Teherani, D. C. Look, and D. J. Rogers (SPIE, San Francisco, 2011), Vol. 7940.

${ }^{29}$ J. D. Ye, S. L. Gu, F. Qin, S. M. Zhu, S. M. Liu, X. Zhou, W. Liu, L. Q. Hu, R. Zhang, Y. Shi, and Y. D. Zheng, Appl. Phys. A: Mater. Sci. Process. 81(4), 759 (2005).

${ }^{30}$ Y. W. Heo, D. P. Norton, and S. J. Pearton, J. Appl. Phys. 98(7), 073502 (2005).

${ }^{31}$ M. D. McCluskey and S. J. Jokela, J. Appl. Phys. 106(7), 071101 (2009).

${ }^{32}$ J. Cizek, J. Valenta, P. Hruska, O. Melikhova, I. Prochazka, M. Novotny, and J. Bulir, Appl. Phys. Lett. 106(25), 251902 (2015).

${ }^{33}$ J. Ji, L. A. Boatner, and F. A. Selim, Appl. Phys. Lett. 105(4), 041102 (2014).

${ }^{34}$ N. O. Korsunska, L. V. Borkovska, B. M. Bulakh, L. Y. Khomenkova, V. I. Kushnirenko, and I. V. Markevich, J. Lumin. 102, 733 (2003).

${ }^{35}$ B. X. Lin, Z. X. Fu, and Y. B. Jia, Appl. Phys. Lett. 79(7), 943 (2001).

${ }^{36}$ C. H. Ahn, Y. Y. Kim, D. C. Kim, S. K. Mohanta, and H. K. Cho, J. Appl. Phys. 105(1), 013502 (2009).

${ }^{37}$ D. M. Hofmann, D. Pfisterer, J. Sann, B. K. Meyer, R. Tena-Zaera, V. Munoz-Sanjose, T. Frank, and G. Pensl, Appl. Phys. A: Mater. Sci. Process. 88(1), 147 (2007).

${ }^{38}$ L. S. Vlasenko and G. D. Watkins, Phys. Rev. B 72(3), 035203 (2005).

${ }^{39}$ L. S. Vlasenko and G. D. Watkins, Phys. Rev. B 71(12), 125210 (2005).

${ }^{40}$ X. J. Wang, L. S. Vlasenko, S. J. Pearton, W. M. Chen, and I. A. Buyanova, J. Phys. D: Appl. Phys. 42(17), 175411 (2009).

${ }^{41}$ L. L. Wu, Y. S. Wu, X. R. Pan, and F. Y. Kong, Opt. Mater. 28(4), 418 (2006).
${ }^{42}$ W. M. Kwok, A. B. Djurisic, Y. H. Leung, D. Li, K. H. Tam, D. L. Phillips, and W. K. Chan, Appl. Phys. Lett. 89(18), 183112 (2006).

${ }^{43}$ N. H. Alvi, K. ul Hasan, O. Nur, and M. Willander, Nanoscale Res. Lett. 6, 130 (2011).

${ }^{44}$ V. Kumar, H. C. Swart, O. M. Ntwaeaborwa, R. E. Kroon, J. J. Terblans, S. K. K. Shaat, A. Yousif, and M. M. Duvenhage, Mater. Lett. 101, 57 (2013).

${ }^{45}$ M. Koyano, P. QuocBao, L. T. ThanhBinh, L. HongHa, N. Ngoclong, and S. Katayama, Phys. Status Solidi A 193(1), 125 (2002).

${ }^{46}$ B. H. Bairamov, A. Heinrich, G. Irmer, V. V. Toporov, and E. Ziegler, Phys. Status Solidi B 119(1), 227 (1983).

${ }^{47}$ C. Sudakar, P. Kharel, G. Lawes, R. Suryanarayanan, R. Naik, and V. M. Naik, J. Phys.: Condens. Matter 19(2), 026212 (2007).

${ }^{48}$ T. A. Harriman, Z. Bi, Q. X. Jia, and D. A. Lucca, Appl. Phys. Lett. 103(12), 121904 (2013).

${ }^{49}$ K. A. Alim, V. A. Fonoberov, and A. A. Balandin, Appl. Phys. Lett. 86(5), 053103 (2005).

${ }^{50}$ M. S. Samuel, J. Koshy, A. Chandran, and K. C. George, Indian J. Pure Appl. Phys. 48(10), 703 (2010).

${ }^{51}$ J. Serrano, F. J. Manjon, A. H. Romero, F. Widulle, R. Lauck, and M. Cardona, Phys. Rev. Lett. 90(5), 055510 (2003).

${ }^{52}$ P. M. Chassaing, F. Demangeot, V. Paillard, A. Zwick, N. Combe, C. Pages, M. L. Kahn, A. Maisonnat, and B. Chaudret, Appl. Phys. Lett. 91(5), 053108 (2007).

${ }^{53}$ S. Filippov, X. J. Wang, M. Devika, N. K. Reddy, C. W. Tu, W. M. Chen, and I. A. Buyanova, J. Appl. Phys. 113(21), 214302 (2013).

${ }^{54}$ K. A. Griffin, A. B. Pakhomov, C. M. Wang, S. M. Heald, and K. M. Krishnan, J. Appl. Phys. 97(10), 10D320 (2005). 